hydrogen chloride. In sulphur dioxide a direct comparison of rates is scarcely possible owing to the one-sidedness of the equilibrium.

The unimolecular replacement in sulphur dioxide ${ }^{4}$,

$$
\mathrm{CHPhMeCl}+\mathrm{I}-=\mathrm{CHPhMeI}+\mathrm{Cl}-\text {, }
$$

is open to the same explanation, since styrene adds hydrogen iodide, which would be formed from the added iodide ions and the liberated hydrogen chloride. Several supposed rearrangements can be similarly re-interpreted.

We are thus able to group all these conductometric, polarimetric, kinetic and other observations under our general mechanism (customarily labelled $E 1)$ for unimolecular elimination reactions :

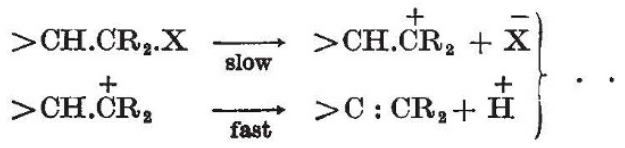

This mechanism assumes that the rate-determining stage is the ionization of the halide, and to this extent we support the inference drawn by previous investigators ${ }^{2,3}$ to the effect that ionization is fundamentally involved. In our mechanism the instability of an alkyl cation containing a potential proton is made responsible for the production of olefin.

Experimental particulars and more extended applications of the $E 1$ mechanism will be published in the Journal of the Chemical Society.

E. D. HUGHES.

University College, London.

C. K. INGOLD. July 1.

A. D. Sсотт.

1 Walden, Ber., 85, 2029 (1802).

Bergmann und Polanyi, Naturwiss., 21, 378 (1933).

Bodendorf und Böhme, Annalen, 5í, 1 (1935).

- Ogg and Polanyi, Trans. Faraday Soc., 31, 617 (1935).

\section{Equilibria in Salt Systems with Deuterium Water}

IN connexion with the letters of Bell ${ }^{1}$, of Partington and Stratton ${ }^{2}$ and with editorial notes ${ }^{3}$, it is of interest to note the degree of activity in this field. As is justly stated in the second letter cited above, "measurements of dissociation pressures of salt hydrates are somewhat difficult". By way of illustration, whereas Perpérot and Schacherl ${ }^{4}$ report a value for the dissociation pressure equilibrium at $25^{\circ}$ of cupric sulphate penta- and tri-deuterates which is 36 per cent lower than the corresponding value for the ordinary hydrates, two of us in 1934 had found this pressure difference to be only 8 per cent. We shall therefore welcome the promised results of Partington and Stratton. We have studied pressure equilibria in this and other univariant salt deuterate systems with and without the liquid phase (saturated solution) present, over a range of temperature.

The solubility relations of salts in deuterium water seem to have received less attention ${ }^{5}$. A few results may perhaps be of interest. If, following "International Critical Tables", concentration is stated in terms of moles of anhydrous solute per 1,000 gm. $\left(55.51\right.$ moles $\left.\mathrm{H}_{2} \mathrm{O}\right)$ in the case of ordinary water, for purposes of comparison we may state the number of moles of solute per $1111 \cdot 7 \mathrm{gm}$. $\left(55 \cdot 51\right.$ moles $\left.\mathrm{D}_{2} \mathrm{O}\right)$ in the case of deuterium water. For potassium chloride on this basis, we find the solubility in deuterium water lower than that in ordinary water

by about 7 per cent at $30^{\circ}, 3.6$ per cent at $100^{\circ}$, and 1.5 per cent at $180^{\circ}$.

In speaking of the solubility of deuterates and hydrates, we refer to solubilities in deuterium water and in ordinary water respectively. Cupric sulphate pentadeuterate is, at $10^{\circ}$, nearly 12 per cent less soluble than pentahydrate; but the difference in solubility falls to about 1.5 per cent near $96^{\circ}$, which is close to the transition temperatures of both salts to their tri-aquo forms. Strontium chloride hexahydrate passes to dihydrate at $61 \cdot 3^{\circ}$, and the hexadeuterate to dideuterate about $56 \cdot 5^{\circ}$. The graph of solubility of hexadeuterate against temperature lies lower in concentration than that of the hexahydrate at lower temperatures but crosses the hexahydrate curve about $10^{\circ}$; the dideuterate solubility curve crosses the hexahydrate curve about $60^{\circ}$ and the dihydrate curve about $115^{\circ}$, both deuterate curves showing a faster change of solubility with temperature than the corresponding hydrate curves.

Princeton University, June 5.
F. T. MHES.

R. W. Shearman.

Alan W. C. Menzies.

1 NATURE, 137, 534 (1936)

NATURE, 137, 707 (1936).

NATURE, 137, 698 (1936)

J. Phys. et le Rad., vil, 6, 439 (1935).

But cf. Taylor, Caley and Eyring, J. Amer. Chem. Soc., 55, 4334 (1933).

\section{Cross-Linkage Formation in Keratins}

THe depilation of hides and skins prior to tannage ${ }^{1}$, and the permanent setting of stretched hair and wool $^{2}$ are both important industrial processes considered to be governed by the development of resistant cross-linkages between the peptide chains of keratins. Speakman ${ }^{2}$ has suggested that when stretched wool fibres are set in steam, the crosslinkages developed consist of $-\mathrm{S}-\mathrm{NH}-$ groupings formed subsequent to the hydrolysis (R.S.S.R. $\rightleftharpoons$ R.SH +HOS.R) of the cystine disulphide crosslinkages; but it is admitted that other resistant linkages must be formed when cross-linking is attended by loss of sulphur.

A possible chemical mechanism, hitherto overlooked, for the production of such resistant linkages may arise by the auto-oxidation-reduction of the sulphenic acid side-chains produced by the hydrolysis of the cystine disulphide cross-linkages. Such decomposition of the sulphenic acid side-chains would yield hydrogen sulphide, and aldehyde groups $\left.>\mathrm{CH} . \mathrm{CH}_{2} \cdot \mathrm{SOH} \rightarrow>\mathrm{CH} . \mathrm{CHO}+\mathrm{H}_{2} \mathrm{~S}\right)$ capable of linking-up with the amino-groups of adjacent peptide chains, for example, those of lysine.

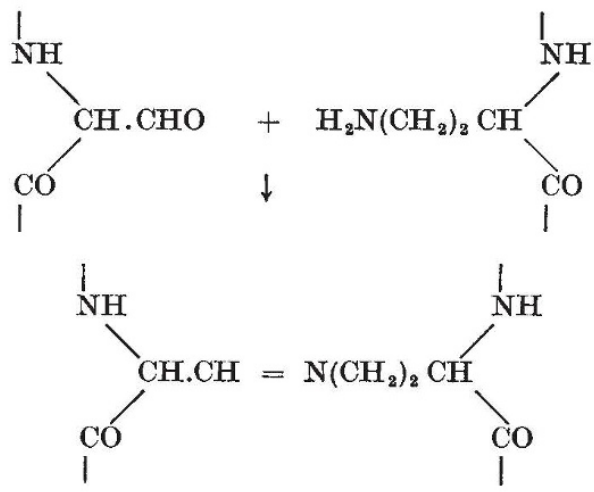

